\title{
Ocean Eddy Energetics in the Spectral Space as Revealed by High-Resolution General Circulation Models
}

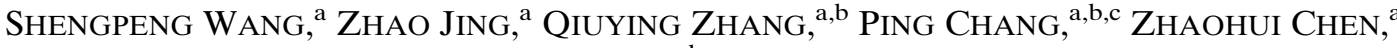 \\ HAILONG LIU, ${ }^{\mathrm{d}}$ AND LIXIN WU ${ }^{\mathrm{a}}$ \\ ${ }^{a}$ Key Laboratory of Physical Oceanography, Institute for Advanced Ocean Studies, Ocean University of China, \\ and Qingdao National Laboratory for Marine Science and Technology, Qingdao, China \\ ${ }^{\mathrm{b}}$ Department of Oceanography, Texas A\&M University, College Station, Texas \\ ${ }^{\mathrm{c}}$ Department of Atmospheric Science, Texas A\&M University, College Station, Texas \\ ${ }^{\mathrm{d}}$ State Key Laboratory of Numerical Modeling for Atmospheric Sciences and Geophysical Fluid Dynamics, \\ Institute of Atmospheric Physics, Chinese Academy of Sciences, Beijing, China
}

(Manuscript received 8 February 2019, in final form 10 June 2019)

\begin{abstract}
In this study, the global eddy kinetic energy (EKE) budget in horizontal wavenumber space is analyzed based on $1 / 10^{\circ}$ ocean general circulation model simulations. In both the tropical and midlatitude regions, the barotropic energy conversion from background flow to eddies is positive throughout the wavenumber space and generally peaks at the scale $\left(L_{e}\right)$ where EKE reaches its maximum. The baroclinic energy conversion is more pronounced at midlatitudes. It exhibits a dipolar structure with positive and negative values at scales smaller and larger than $L_{e}$, respectively. Surface wind power on geostrophic flow results in a significant EKE loss around $L_{e}$ but deposits energy at larger scales. The interior viscous dissipation and bottom drag inferred from the pressure flux convergence act as EKE sink terms. The latter is most efficient at $L_{e}$ while the former is more dominant at smaller scales. There is an evident mismatch between EKE generation and dissipation in the spectral space especially at the midlatitudes. This is reconciled by a dominant forward energy cascade on the equator and a dominant inverse energy cascade at the midlatitudes.
\end{abstract}

\section{Introduction}

Oceanic eddies are ubiquitous in the upper ocean, as evidenced by the satellite observations and eddy-resolving model simulations over the past two decades. About $70 \%$ of the ocean kinetic energy is stored in the eddy field (von Storch et al. 2012). Many efforts have been devoted to understanding the generation, propagation, and dissipation of eddies, as well as their impacts on the transport of mass, nutrients, salt, and heat (e.g., Stammer 1998; Chelton et al. 2011; Meijers et al. 2007; Jayne and Marotzke 2002; Sumata et al. 2010).

To a large extent, oceanic eddies are geostrophically balanced. Their characters and dynamics are better understood from the perspective of two-dimensional (2D) turbulence theory or the geostrophic turbulence theory (Charney 1971; Rhines 1977). The 2D turbulence theory predicts an inverse kinetic energy cascade

Corresponding author: Zhao Jing, jingzhao198763@sina.com
(Fjørtoft 1953) and has been confirmed by satellite observations and high-resolution numerical simulations off the equatorial ocean (e.g., Scott and Wang 2005; Schlösser and Eden 2007; Wang et al. 2015). Furthermore, the inverse kinetic energy cascade implies that the energy input into eddies has to be dissipated at basin scales. Possible routes to dissipation for such large-scale motions include bottom friction, lee-wave generation, topographic inviscid dissipation of balanced flow, and gravity wave drag on the balanced flow (Arbic et al. 2009; Bell 1975; Nikurashin and Ferrari 2011; Dewar and Hogg 2010). However, it is poorly assessed whether the dissipation at basin scales is efficient enough to balance the energy input into the eddy field.

In addition to the inverse kinetic energy cascade predicted by the $2 \mathrm{D}$ turbulence theory, numerical simulations also reveal a robust forward kinetic energy cascade in the submesoscale range where the Rossby number of eddies becomes $O(1)$ (Capet et al. 2008; 
Molemaker et al. 2010; Tulloch et al. 2011). The forward kinetic energy cascade is suggested to be partly associated with the ageostrophic dynamics and thus cannot be fully captured by the 2D turbulence theory (Brüggemann and Eden 2015). As the viscous effect becomes dominant at small scales, the forward kinetic energy cascade provides an efficient way to transfer the kinetic energy to scales where dissipative processes can take over (Kolmogorov 1991; Wunsch and Ferrari 2004). A recent ideal modeling study by Barkan et al. (2015) suggests that the dissipation of kinetic energy at small scales might be more effective than the energy loss at large scales due to bottom drag through the inverse energy cascade, highlighting the important role of forward kinetic energy cascade in dissipating kinetic energy.

Despite the significant kinetic energy cascade due to the nonlinear eddy-eddy interactions, previous eddy energy budget analyses are generally performed in the physical space (e.g., von Storch et al. 2012; Chen et al. 2014; Wu et al. 2017). In these analyses, there is no explicit term accounting for the kinetic energy cascade so that its influence on the eddy energetics remains unclear. To address this problem, we analyze the global eddy kinetic energy budget in the horizontal wavenumber domain (referred to as the spectral EKE budget) based on $1 / 10^{\circ}$ ocean general circulation model simulations.

This paper is organized as follows. Section 2 briefly describes the model and the methodology used in this study. The global EKE spectrum and spectral EKE budget analysis are presented in section 3 . Finally, discussion is provided in section 4 followed by conclusions in section 5 .

\section{Data and methodology}

a. Data

To compute the spectral EKE budget, an eddyresolving global climate simulation based on the Community Earth System Model (CESM) developed by National Center for Atmospheric Research (NCAR) is used in this study. The model configuration includes the Community Atmosphere Model version 5 (CAM5) with a spectral element dynamical core, the Parallel Ocean Program version 2 (POP2), as well as sea ice and land models (Small et al. 2014). CAM5 and POP2 have horizontal resolutions of $\sim 0.25^{\circ}$ and $\sim 0.1^{\circ}$, respectively. For POP2, there are 62 levels in the vertical with increasing grid space from $5 \mathrm{~m}$ near the sea surface to $250 \mathrm{~m}$ near the bottom. Scale-selected Laplacian and biharmonic mixing options are used for momentums and tracers. The Laplacian viscosity (diffusion) coefficient is set at
$1 \times 10^{4} \mathrm{~m}^{2} \mathrm{~s}^{-1}\left(1 \times 10^{4} \mathrm{~m}^{2} \mathrm{~s}^{-1}\right)$, and the biharmonic viscosity (diffusion) coefficient is set at $27 \times 10^{9} \mathrm{~m}^{4} \mathrm{~s}^{-1}$ $\left(3 \times 10^{9} \mathrm{~m}^{4} \mathrm{~s}^{-1}\right)$. The ocean model provides SST and surface current velocity to the atmosphere model and receives updated fluxes from the atmosphere model calculated using the Large and Yeager surface layer scheme every $6 \mathrm{~h}$ (Small et al. 2014; Bishop et al. 2015). Small et al. (2014) analyzed the results of a 100-yr simulation of the high-resolution CESM with 14 years of spinup (86 years without the spinup). In this study, we extended this integration from 1 January of year 87 to 30 April of year 91, and outputted daily averaged threedimensional (3D) temperature, salinity, and velocity, as well as all the surface fluxes and diagnostic terms in the momentum equation, so that the eddy kinetic energy budget can be analyzed.

To evaluate the validity of the spectral EKE budget derived from CESM, one of the hindcast runs of the State Key Laboratory of Numerical Modeling for Atmospheric Sciences and Geophysical Fluid Dynamics/Institute of Atmospheric Physics (LASG/IAP) Climate System Ocean Model 2.0 (LICOM) (Yu et al. 2012; Liu et al. 2014) is also used in this study. The quasi-global model domain extends from $66^{\circ} \mathrm{N}$ to $79^{\circ} \mathrm{S}$ and from $180^{\circ}$ to $180^{\circ}$, with a horizontal resolution of $0.1^{\circ}$. There are 55 levels in the vertical direction with thickness increasing from $2.5 \mathrm{~m}$ near the sea surface to $400 \mathrm{~m}$ near the bottom. The scale-selected biharmonic friction and diffusion schemes are used for momentums and tracers (temperature and salinity), respectively. The biharmonic viscosity coefficient is $2.4 \times 10^{9} \mathrm{~m}^{4} \mathrm{~s}^{-1}$, and the biharmonic diffusion coefficient is $2.7 \times 10^{10} \mathrm{~m}^{4} \mathrm{~s}^{-1}$. This eddy-resolving OGCM is first spun up for 12 years from the Ocean Model International Cooperation Program (OMIP) (Roske 2001), which is derived from the European Centre for Medium-Range Weather Forecasts (ECMWF) ERA-15 reanalysis product (Gibson et al. 1999). After this spinup integration, a $60-\mathrm{yr}$ (1948-2007) hindcast integration is conducted using the daily mean atmospheric forcing from the Coordinated Ocean-Ice Reference Experiments (CORE) version 2 (Large and Yeager 2004). In this study, the daily output (one snapshot every day) from 1 January 1990 to 31 December 1996 is used. However, as the diagnostic output is not available for this hindcast run, not all the components (e.g., the viscous dissipation term and pressure flux term) in the spectral EKE budget can be evaluated.

\section{b. Spectral eddy kinetic energy budget analysis}

In this study, we perform a Reynolds decomposition of the 3D flow field into mean flow and eddy perturbations: $\mathbf{u}=\mathbf{u}^{\prime}+\overline{\mathbf{u}}$, where the mean flow is computed as the time 
average (von Storch et al. 2012; Zhai and Marshall 2013; Chen et al. 2014). One caveat is that such defined eddy perturbations include the seasonal variability. However, we found that the contamination of the spectral EKE budget by seasonal variability is negligible.

The spectral EKE budget is derived as follows:

$$
\begin{aligned}
& \partial_{t} \overline{\mathrm{EKE}_{K}}=\underbrace{\Re \overline{\left(-\frac{g}{\left.\rho_{0} \widehat{w}^{\prime *} \widehat{\rho}^{\prime}\right)}\right.}}_{\mathrm{IKE}_{K}}+\underbrace{\Re \overline{\left[{ }_{\left[-\widehat{\mathbf{u}}_{h}^{*}\right.}^{*} \cdot \overline{\left(\mathbf{u}^{\prime} \cdot \nabla\right) \overline{\mathbf{u}}_{h}}\right]}}_{\mathrm{MKE}_{K}}
\end{aligned}
$$

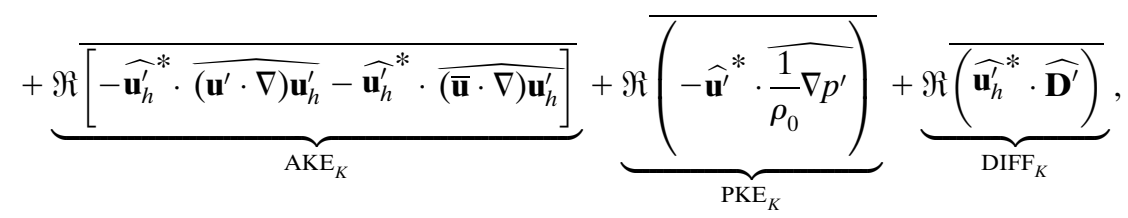

where $\mathbf{u}=(u, v, w)$ is the $3 \mathrm{D}$ velocity, $\nabla$ is the divergence operator, $\mathbf{D}$ represents the viscous terms for zonal and meridional velocities, $p$ is the hydrostatic pressure, $\rho$ is the density, $\rho_{0}$ is the reference density chosen to be $1027.5 \mathrm{~kg} \mathrm{~m}^{-3}, \hat{\therefore}$ denotes the $2 \mathrm{D}$ Fourier transform, $*$ is the complex conjugate, $\Re$ is the real part operator, and the overbar represents the average over time. $\mathrm{EKE}_{K}=\mathfrak{R}\left[(1 / 2) \widehat{\mathbf{u}_{h}^{\prime}} \widehat{\mathbf{u}_{h}^{\prime}}\right]$ is the power spectral density of EKE, where the subscript $K$ denotes the magnitude of the wave vector $\left(k_{x}, k_{y}\right) . \mathrm{AKE}_{K}$ and $\mathrm{PKE}_{K}$ represent the change of EKE through advection and pressure work, respectively. $\mathrm{IKE}_{K}$ is the conversion of eddy available potential energy (EAPE) to $\mathrm{EKE}_{K}$. $\mathrm{MKE}_{K}$ represents the kinetic energy exchange between eddy perturbations and mean flow. $\mathrm{DIFF}_{K}$ denotes the change of EKE $_{K}$ due to the viscous effect. ${ }^{1}$

Equation (1) is analogous to the spectral kinetic energy budget derived by Capet et al. (2008) except for the additional term $\mathrm{MKE}_{K}$. This is because Capet et al. (2008) analyzes the kinetic energy budget of total flow so that there is no energy transfer through $\mathrm{MKE}_{K}$. To calculate the spectral EKE budget, a 2D Fourier decomposition is implemented onto individual halfoverlapping subdomains. Each subdomain has 128 grid points in the zonal direction and meridional direction. To avoid the calculation error due to the land grid, the spectral EKE budget is only computed in a subdomain without the land grid. The subdomains are large enough to capture the eddy energy containing scales but are small enough to avoid strong spatial nonstationarity. To reduce the Gibbs effect, variables are first detrended in space and then tapered by a $2 \mathrm{D}$ window function

\footnotetext{
${ }^{1}$ In this manuscript, the viscous effect combines the terms related to the vertical viscosity, horizontal viscosity, and horizontal biharmonic viscosity. The wind forcing is included in the term related to the vertical viscosity as its surface boundary condition.
}

composed of nine half-overlapping Hanning windows before the Fourier transform following Scott and Wang (2005). However, it should be noted that such a taper function might reduce the entire variance in the signal, which tends to underestimate the magnitude of individual terms in the spectral EKE budget. Nevertheless, these biases are tolerable for our qualitative analysis. Finally, as we focus on the dependence of EKE budget on the magnitude of the wave vector instead of its direction, the $2 \mathrm{D}$ wavenumber spectra are transformed into the $1 \mathrm{D}$ wavenumber spectra by integrating the azimuth of wave vector out.

\section{c. Flux of EKE in the spectral space}

The $\mathrm{AKE}_{K}$ term is a combination of the redistribution of EKE among different wavenumbers through the nonlinear eddy-eddy interactions and the transport of EKE out of or into the domain through the boundaries (Klein et al. 2008). If the latter were absent, the flux of EKE in the spectral space, that is, the energy cascade, could be evaluated by integrating the $\mathrm{AKE}_{K}$ term with respect to $K$ (Capet et al. 2008; Marchesiello et al. 2011):

$$
\Pi(K)=\int_{K}^{K_{\max }} \mathrm{AKE}_{k} d k
$$

where $\Pi(K)$ is assumed to vanish at the highest wavenumber $K_{\max }$. It should be noted that there are other methods for the calculation of the EKE spectral flux in real ocean (Scott and Wang 2005; Schlösser and Eden 2007; Ni et al. 2014). However, the method adopted in this study is compatible to the spectral EKE budget equation. Furthermore, the main result is found insensitive to the adopted computational methods.

In general, there might be a net transport of EKE across the boundary, contaminating the energy cascade inferred from Eq. (2). As demonstrated in appendix B, such contamination seems to be minor and is unlikely 

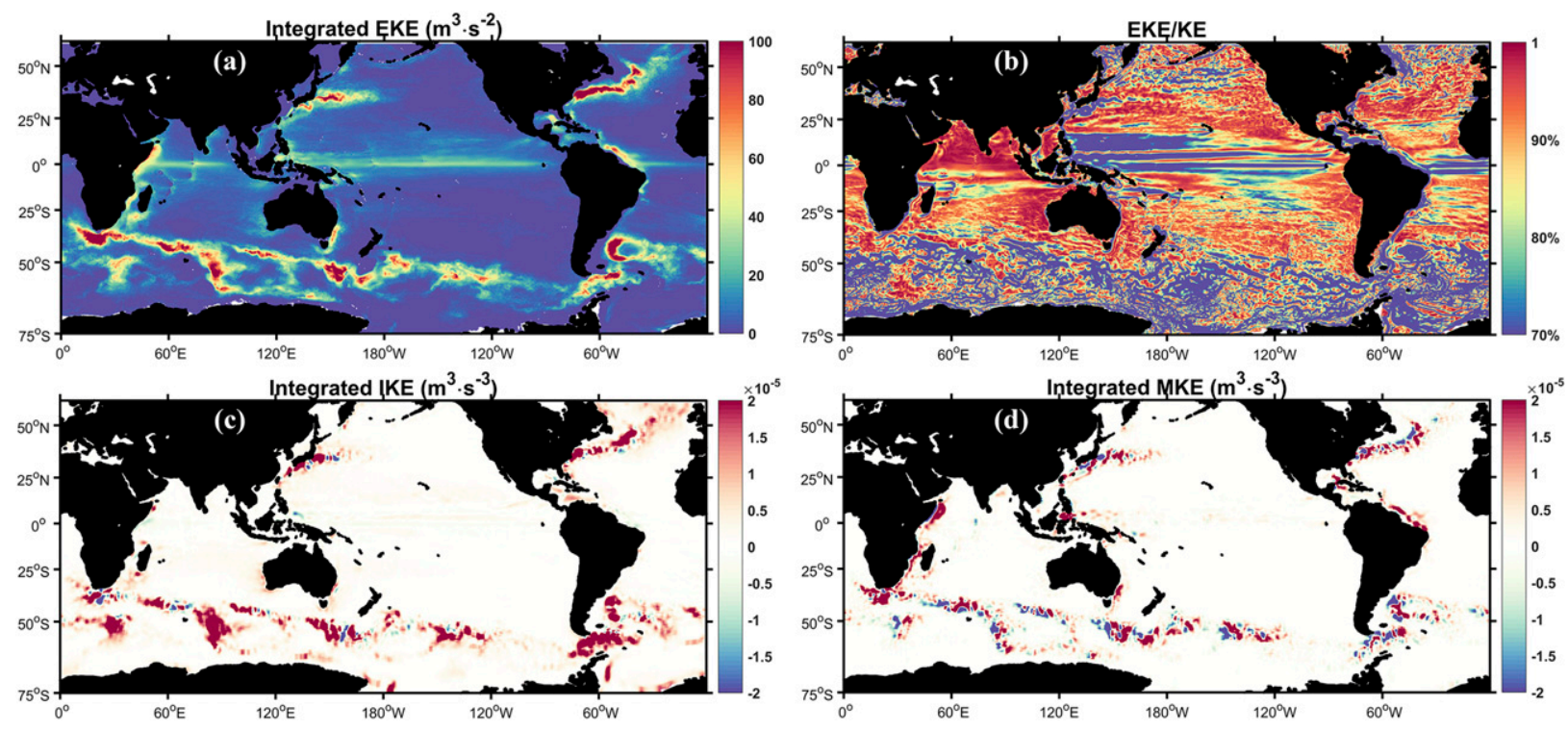

FIG. 1. (a) Vertically integrated eddy kinetic energy, (b) the ratio of the vertically integrated eddy kinetic energy to the total kinetic energy, (c) vertically integrated baroclinic conversion, and (d) vertically integrated barotropic conversion derived from the 4-yr CESM simulations.

to have a substantial impact on the qualitative features of the inferred energy cascade from Eq. (2).

\section{d. Vertical integration of spectral EKE budget}

The ocean bottom topography imposes difficulties in interpreting the vertical integration of spectral EKE budget due to the effect of bottom drag. When the sea floor within a subdomain is flat, the contribution of bottom drag to the vertically integrated spectral EKE budget is fully contained in the $\mathrm{DIFF}_{K}$ term when the lower bound of vertical integration is set as the ocean bottom but is in the $\mathrm{PKE}_{K}$ term when the lower bound is above the bottom boundary layer (see appendix A for details). For an uneven sea floor, no lower integration bound can be chosen to make the contribution of the bottom drag go into the $\mathrm{DIFF}_{K}$ term. Therefore, the lower bound for each subdomain is defined as the last but one model depth level at which the subdomain does not contain any land point. In this case, the contribution of bottom drag is mainly contained in the $\mathrm{PKE}_{K}$ term.

\section{Results}

\section{a. Eddy energetics in the physical space}

The distribution of the vertically integrated EKE in physical space is shown in Fig. 1a. Over the global ocean, more than $70 \%$ of ocean kinetic energy is stored in the oceanic eddies (Fig. 1b). Large EKE values are found in the western boundary currents and their extensions,
Antarctic Circumpolar Current (ACC) and equatorial band (Fig. 1a), which is consistent with the observation from the satellite and numerical simulations (Chelton et al. 2011; von Storch et al. 2012; Chen et al. 2014). The energetic eddies in these regions coincide with strong positive baroclinic conversion $\overline{w^{\prime} b^{\prime}}$ and barotropic conversion $-\left(\overline{u^{\prime} \mathbf{u}^{\prime}} \cdot \nabla \bar{u}+\overline{v^{\prime} \mathbf{u}^{\prime}} \cdot \nabla \bar{v}\right)$ (Figs. 1c,d). The results derived from the CESM agree with those presented by Chen et al. (2014) using an eddypermitting OGCM.

\section{b. Eddy energetics in the spectral space}

\section{1) LATITUdinAL DisTRIBUTION OF THE SPECTRAL EKE BUDGET}

The EKE spectrum exhibits enhancement in the latitude bands $40^{\circ}-55^{\circ} \mathrm{S}, 5^{\circ} \mathrm{S}-5^{\circ} \mathrm{N}, 28^{\circ}-42^{\circ} \mathrm{N}$, and $30^{\circ}-45^{\circ} \mathrm{N}$ corresponding to the energetic eddy activities in the ACC, equatorial region, Kuroshio extension, and Gulf Stream extension, respectively (Fig. 2a). So is the case for individual terms in the spectral EKE budget (Figs. 2b-f and 4b-f). The $\mathrm{MKE}_{K}$ term has similar magnitudes and spectral shapes in all these latitude bands. It is characterized by a pronounced positive peak around the eddy energy containing scale $L_{e}$, defined as the scale where the $\mathrm{EKE}_{K}$ is at maximum (Figs. 2a and 4a). In contrast, the $\operatorname{IKE}_{K}$ term is more significant at the midlatitudes than in the equatorial region. It exhibits a dipolar structure with positive (negative) values at scales smaller (larger) than $L_{e}$, respectively. However, as 

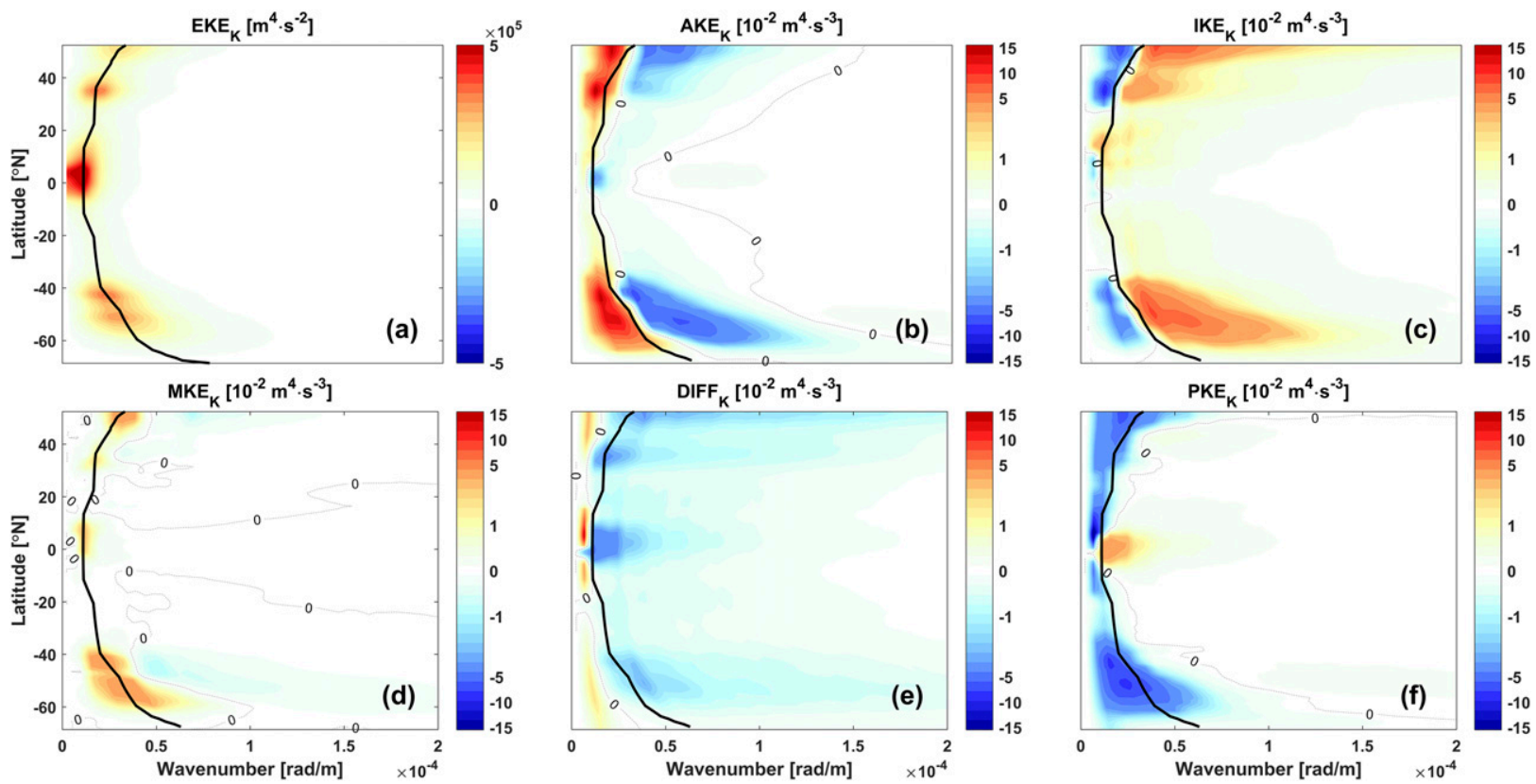

FIG. 2. Vertically integrated (a) $\mathrm{EKE}_{K}$, (b) $\mathrm{AKE}_{K}$, (c) $\mathrm{IKE}_{K}$, (d) $\mathrm{MKE}_{K}$, (e) $\mathrm{DIFF}_{K}$, and (f) $\mathrm{PKE}_{K}$. The black solid line is the eddy energy containing wavenumber $1 / L_{e}$. The results are derived from the 4-yr CESM simulations.

the positive lobe is more dominant, the net contribution of $\mathrm{IKE}_{K}$ term is to convert EAPE into EKE.

The DIFF $_{K}$ term plays a dual role in the spectral EKE budget. It dissipates the EKE at scales around and smaller than $L_{e}$ whereas it contributes to the generation of EKE at larger scales. To better understand the role of $\mathrm{DIFF}_{K}$ term, we further decompose it into the surface wind power on geostrophic flow $W_{K}^{G}$ and interior dissipation $\operatorname{DIFF}_{K}^{\text {int }}$ (see appendix A for details). As the geostrophic relation breaks down around the equator, we only compute the $W_{K}^{G}$ poleward of $6.4^{\circ}$. As shown in Fig. 3, $W_{K}^{G}$ is responsible for the EKE input through $\mathrm{DIFF}_{K}$ term at scales larger than $L_{\mathrm{e}}$. Moreover, it provides a significant loss of EKE around $L_{e}$ due to the imprint of ocean eddy current on wind stress (Chelton et al. 2004; Scott and Xu 2009; Frenger et al. 2013). As expected, the DIFF ${ }_{K}^{\text {int }}$ term leads to EKE loss throughout the wavenumber and is more dominant at scales smaller than $L_{e}$

The $\mathrm{PKE}_{K}$ term behaves differently in the equatorial and midlatitude regions (Figs. $2 \mathrm{f}$ and $4 \mathrm{f}$ ). At the midlatitudes, it acts as a significant EKE sink at scales
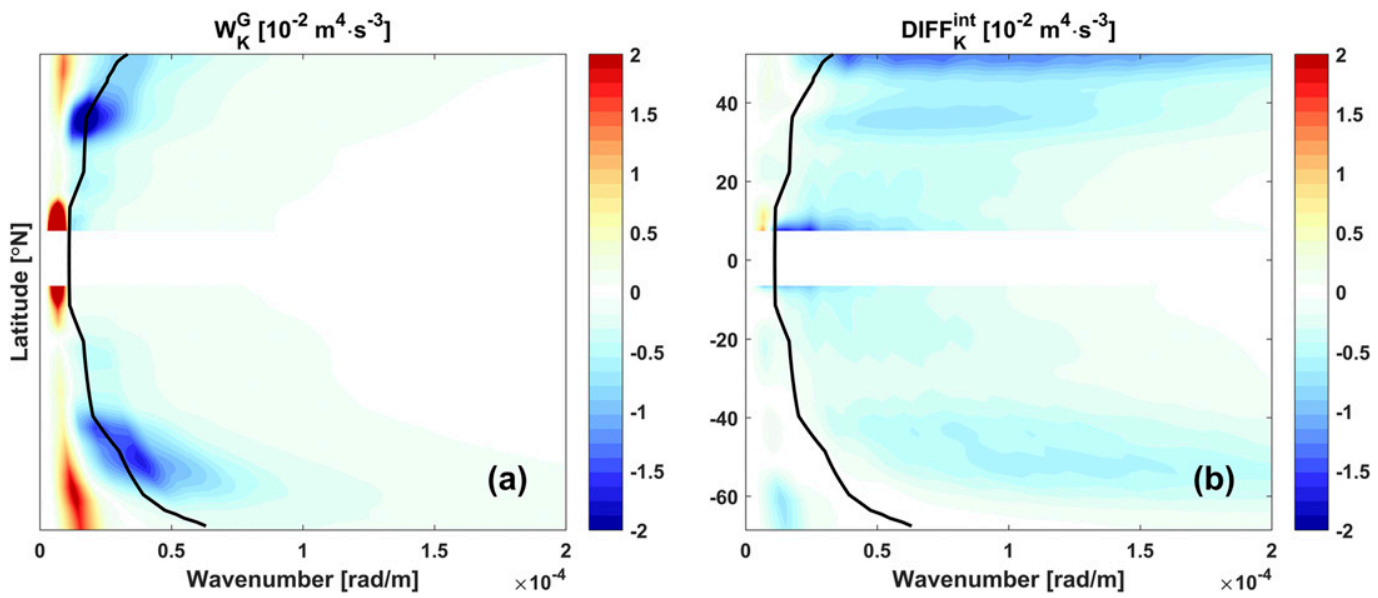

FIG. 3. Vertically integrated (a) $W_{K}^{G}$ and (b) DIFF ${ }_{K}^{\text {int }}$. The black solid line is the eddy energy containing wavenumber $1 / L_{e}$. The results are derived from the 4-yr CESM simulations. 


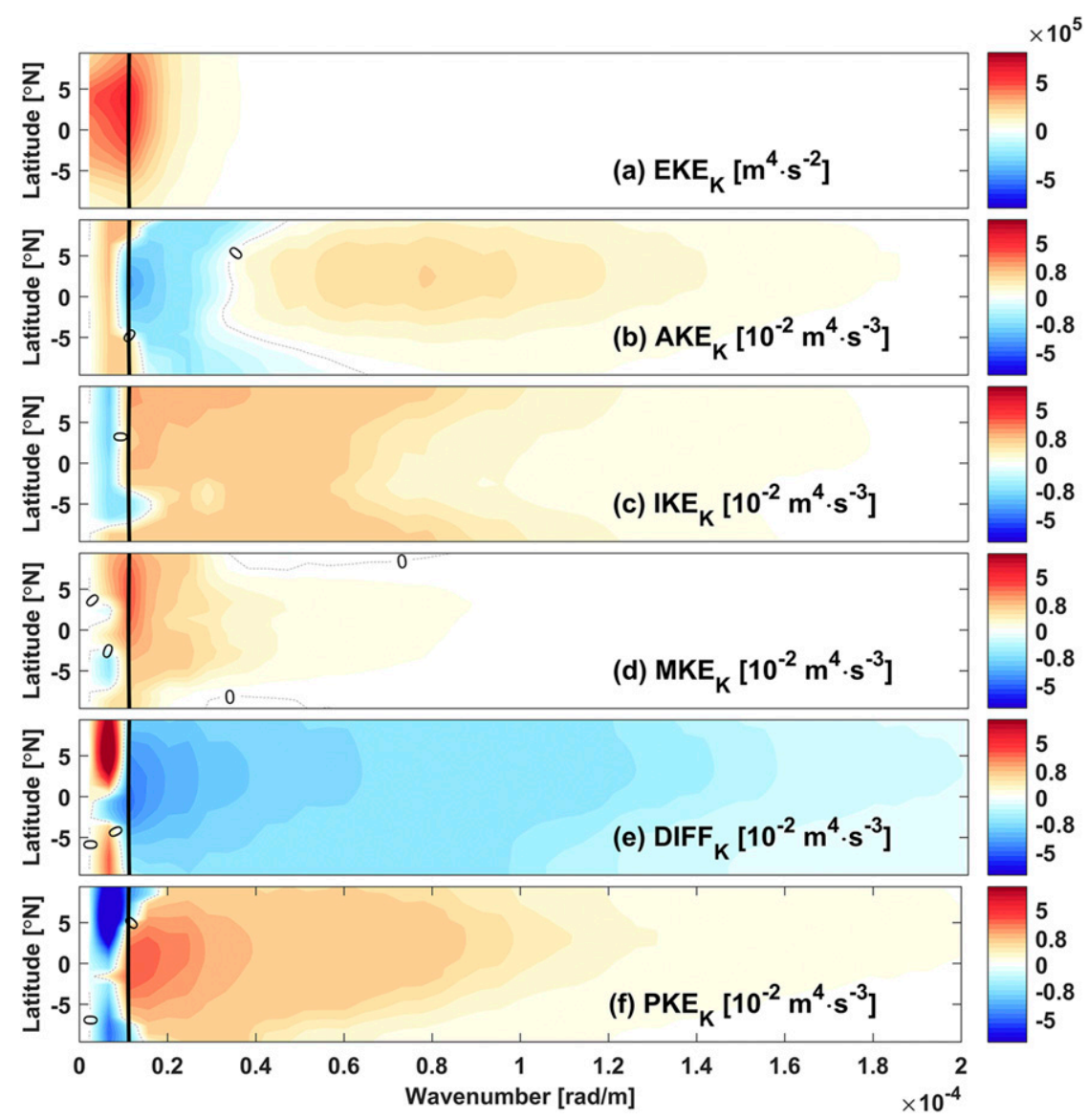

FIG. 4. As in Fig. 2, but for the equatorial region $\left(<10^{\circ}\right)$.

around and larger than $L_{e}$ probably by radiating EKE from the ocean interior downward to the bottom boundary layer where EKE is dissipated by the bottom drag (Roullet et al. 2012). Near the equator, the $\mathrm{PKE}_{K}$ term results in significant EKE gain at scales smaller than $L_{e}$. This may be related to the equatorward radiation of EKE from the off-equatorial region to maintain the background flow against vertical mixing (Holmes and Thomas 2016).

The energy injection and dissipation by $\mathrm{MKE}_{K}, \mathrm{IKE}_{K}$, $\mathrm{DIFF}_{K}$, and $\mathrm{PKE}_{K}$ are largely balanced if integrated over all the wavenumbers. However, there is an evident scale mismatch between energy sources and sinks in the spectral space (Table 1). At the midlatitudes, there is a net EKE gain of $9.0 \mathrm{~mW} \mathrm{~m}^{-2}$ and a net EKE loss of $8.6 \mathrm{~mW} \mathrm{~m}^{-2}$ at scales smaller and larger than $L_{e}$, respectively. Such imbalance is reconciled by the $\mathrm{AKE}_{K}$ term that results in a significant inverse energy cascade at $L_{e}$ (Figs. $5 \mathrm{a}-\mathrm{c}$ ), consistent with the geostrophic turbulence theory and satellite observations. In contrast, the equatorial region is associated with a net EKE loss of $0.6 \mathrm{~mW} \mathrm{~m}^{-2}$ at scales smaller than $L_{e}$ and a net EKE gain of $0.6 \mathrm{~mW} \mathrm{~m}^{-2}$ at scales larger than $L_{e}$. The EKE budget balance in the spectral space is achieved through the forward energy cascade at $L_{e}$ induced by the $\mathrm{AKE}_{K}$ term (Fig. 5d). This dominant forward energy cascade is mainly ascribed to the much reduced Coriolis parameter that makes eddy motions there subject to submesoscale dynamics with a Rossby number of $O(1)$ (Wang et al. 2018). In a word, the nonlinear eddy-eddy interactions are crucial for maintaining the equilibrium state of oceanic eddies. We remark that the important role of nonlinear eddy-eddy interactions in the EKE budget can only be manifested in the energy budget analysis in the spectral space.

\section{2) VERTICAL DISTRIBUTION OF SPECTRAL EKE BUDGET}

In this subsection, we analyze the vertical distribution of the spectral EKE budget. Given that the spectral EKE budgets in the midlatitude and equatorial regions differ significantly, we evaluate them separately. At midlatitudes, the $\mathrm{MKE}_{K}$ term peaks at the sea surface and decays with the depth (Fig. 6d), consistent with the 
TABLE 1. Production and destruction of EKE $\left(\mathrm{mW} \mathrm{m}^{-2}\right)$ at scales larger and smaller than the eddy energy containing scale $L_{e}$ in the midlatitude and equatorial regions. The values are obtained by integration of individual terms first over the depth and then over the selected wavenumber range.

\begin{tabular}{lcc}
\hline \hline & Scales smaller than $L_{e}$ & Scales larger than $L_{e}$ \\
\hline \multicolumn{3}{c}{ Midlatitude region } \\
$\mathrm{MKE}_{K}$ & 0.0 & 2.0 \\
$\mathrm{IKE}_{K}$ & 17.0 & -2.2 \\
$\mathrm{DIFF}_{K}$ & -8.8 & -0.2 \\
$\mathrm{PKE}_{K}$ & 0.3 & -8.7 \\
$\mathrm{AKE}_{K}$ & -8.6 & 9.0 \\
$\partial_{t} \mathrm{EKE}_{K}$ & -0.1 & -0.1 \\
& & \\
$\mathrm{MKE}_{K}$ & Equatorial region & 1.2 \\
$\mathrm{IKE}_{K}$ & 1.0 & -0.1 \\
$\mathrm{DIFF}_{K}$ & 2.8 & -0.8 \\
$\mathrm{PKE}_{K}$ & -10.5 & 0.4 \\
$\mathrm{AKE}_{K}$ & 6.1 & -0.6 \\
$\partial_{t} \mathrm{EKE}_{K}$ & 0.6 & 0.1 \\
\hline
\end{tabular}

surface intensified $\mathrm{EKE}_{K}$ (Fig. 6a) as a rough measurement of intensity of eddy-induced stress acting on the background flow. Similar is the case for the $\mathrm{AKE}_{K}$ term. In contrast, the $\mathrm{IKE}_{K}$ term exhibits two peaks: one centered around the main thermocline at $500-600 \mathrm{~m}$ with a broad vertical structure and the other confined in the upper $100 \mathrm{~m}$. The first peak is consistent with the low-vertical-mode baroclinic instability associated with the deep density front in the Kuroshio extension, Gulf Stream extension and ACC (Smith 2007). However, different from the classical linear instability theory (Eady 1949; Charney 1971), the $\mathrm{IKE}_{K}$ term exhibits a dipole mode with positive and negative values at scales smaller and larger than $L_{e}$, respectively. We note that such a dipolar structure is also found in idealized numerical simulations by Roullet et al. (2012). Dubovikov and Canuto (2005) explain it as a probable consequence of a mesoscale eddy production on large scale. This dipole mode in the main thermocline is responsible for the dipolar structure of the vertically integrated $\mathrm{IKE}_{K}$ term shown in Fig. 2. The second peak of $\mathrm{IKE}_{K}$ term is almost positive definite and has a much broader extent in the wavenumber space. The underlying dynamics for this shallow peak remain unclear and are currently under investigation. The $\mathrm{DIFF}_{K}$ term is mainly confined to the surface mixed layer as a result of strong turbulent viscosity there. The $\mathrm{PKE}_{K}$ term plays an important role in distributing the energy vertically, reconciling the mismatch between the energy sources and sinks in the vertical distribution. Specifically, the ocean interior is dominated by a pressure flux divergence that is compensated by the convergence in the surface and bottom boundary layers. ${ }^{2}$ This radiates EKE from the ocean interior where bulk of the EKE is produced to the surface and bottom boundary layers where the turbulent viscous dissipation is most efficient (Roullet et al. 2012).

The vertical distribution of the spectral EKE budget in the equatorial region differs significantly from that at the midlatitudes (Fig. 7). The $\mathrm{MKE}_{K}$ term is generally positive and confined to the upper $150 \mathrm{~m}$, consistent with the strong lateral shear between the Equatorial Undercurrent and the Southern Equatorial Currents (Philander 1978; Holmes and Thomas 2016). The $\mathrm{IKE}_{K}$ term is not vertically coherent. It is positive in the upper $80 \mathrm{~m}$. But this EAPE-to-EKE conversion is partly cancelled by the reversed conversion in the deeper region. Both the $\mathrm{IKE}_{K}$ term and the $\mathrm{MKE}_{K}$ term near the equator exhibit a pronounced seasonal cycle with the larger values occurring in boreal autumn (Fig. 8), when the motions of the tropical instability waves and the submesoscale eddies are active (Holmes and Thomas 2016; Wang et al. 2018). Such seasonal variations and vertical structures are similar to the findings in the regional and global oceanic simulations (Holmes and Thomas 2016; Wang et al. 2018). The $\mathrm{DIFF}_{K}$ term exhibits two negative peaks in the vertical direction at scales smaller than $L_{e}$. In addition to the shallow peak within the surface boundary layer, there is another peak centered around $100 \mathrm{~m}$. This deep peak is probably due to strong dissipation resulting from the KelvinHelmholtz instability triggered by the vertical shear of Equatorial Undercurrent (Jones 1973; Liu et al. 2016). The vertical structure of $\mathrm{PKE}_{K}$ term is more complicated in the equatorial region than at the midlatitudes with staggered pressure flux convergence/divergence. Such a pattern could be a combined effect from several processes such as the radiation of EKE from the ocean interior to boundary layers and from the off-equatorial region to the equator (Masina et al. 1999; Holmes and Thomas 2016). It must be noted that the $\mathrm{PKE}_{K}$ term may be more pronounced within the equatorial waveguide, which could not be easily excluded in spectral EKE analysis here.

\section{Discussion}

An important finding obtained from the spectral EKE budget is the scale-dependent role of baroclinic

\footnotetext{
${ }^{2}$ The $\mathrm{PKE}_{K}$ term in the bottom boundary layer cannot be directly computed due to the uneven sea floor. But its value can be inferred based on the fact that the integral of $\mathrm{PKE}_{K}$ term over the entire ocean is zero.
} 

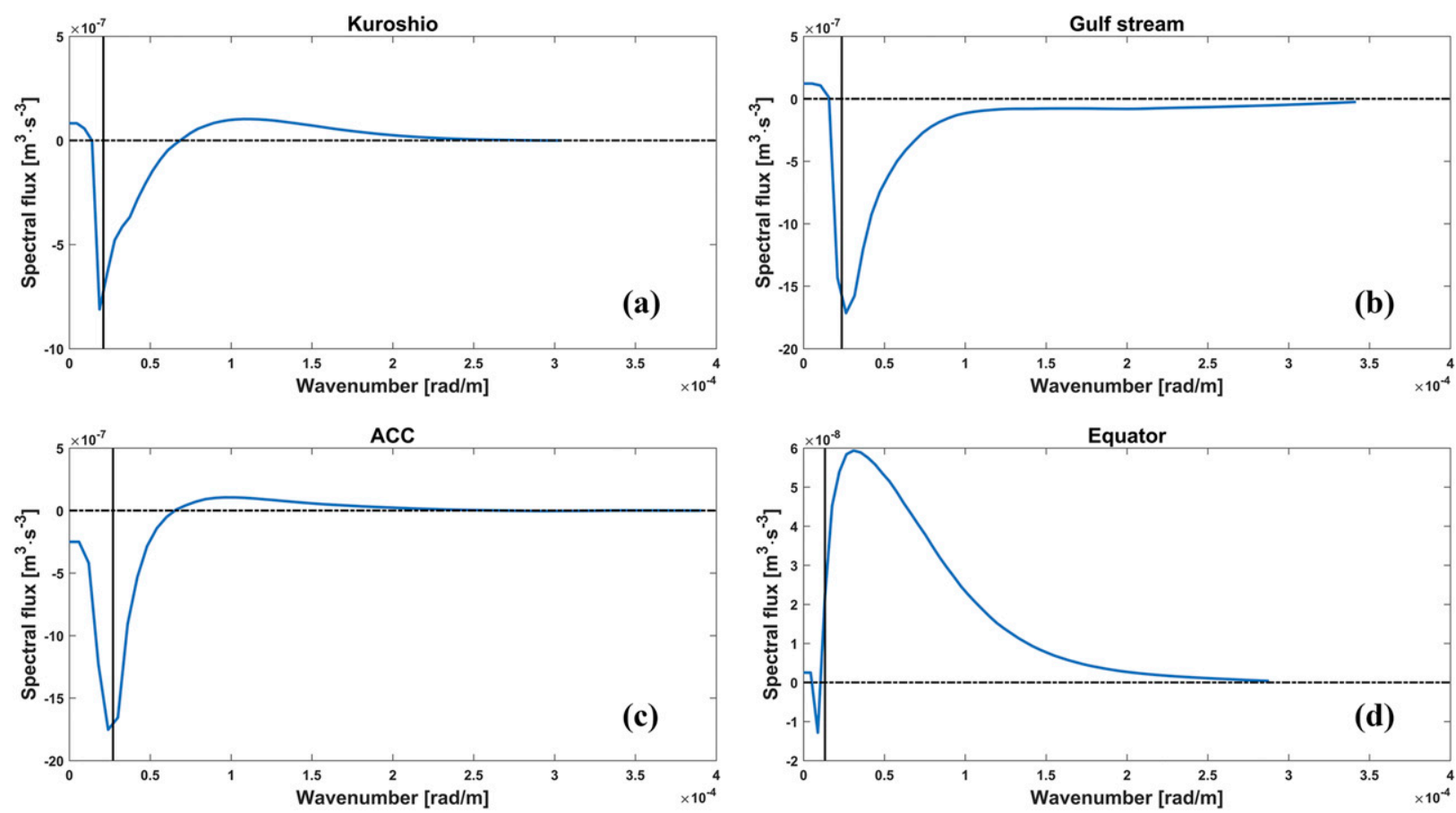

FIG. 5. Vertically integrated spectral flux $\Pi(K)$ in the (a) Kuroshio Extension $\left(28^{\circ}-42^{\circ} \mathrm{N}, 145^{\circ}-180^{\circ} \mathrm{E}\right)$, (b) Gulf Stream extension $\left(30^{\circ}-43^{\circ} \mathrm{N}, 45^{\circ}-75^{\circ} \mathrm{W}\right),(\mathrm{c}) \mathrm{ACC}\left(35^{\circ}-50^{\circ} \mathrm{S}, 50^{\circ}-120^{\circ} \mathrm{E}\right)$, and (d) equatorial region $\left(10^{\circ} \mathrm{S}-10^{\circ} \mathrm{N}, 95^{\circ}-165^{\circ} \mathrm{W}\right)$. The vertical line is the eddy energy containing wavenumber $1 / L_{e}$.

conversion $\left(\mathrm{IKE}_{K}\right.$ term) at midlatitudes. It produces EKE at scales smaller than $L_{e}$ but acts as an EKE sink at larger scales by transferring the energy from the eddy field to background flow. Such a feature is inconsistent with the classical geostrophic turbulence theories. Integrated between 0 and $L_{e}$, the EKE loss at large scales through the baroclinic conversion is $0.044 \mathrm{TW}$, about $14 \%$ of the EKE gain $(0.31 \mathrm{TW})$ through the baroclinic conversion at small scales. This EKE loss plays an important role in balancing the EKE budget at large scales, accounting for $29 \%$ of the energy input into the large scales through the inverse energy cascade. Thus, without the EKE sink due to the baroclinic conversion, a stronger viscous dissipation would be needed to close the energy budget at large scales. This would lead to a higher EKE level at large scales as the viscous dissipation intensity is proportional to the EKE level. Therefore, the EKE sink due to the baroclinic conversion plays an important role in shaping the EKE level at large scales.

To test whether the dipolar structure of $\mathrm{IKE}_{K}$ term in CESM is a robust feature, we repeat the computation using the LICOM simulations. The results derived from the CESM and LICOM are qualitatively consistent with each other (Fig. 9). In specific, the vertically integrated $\mathrm{IKE}_{\mathrm{K}}$ term in LICOM also exhibits a dipole mode at the midlatitudes with positive and negative values at scales larger and smaller than $L_{e}$, respectively. This provides further evidence that the baroclinic conversion term transfers energy from eddies to background flow at scales larger than $L_{e}$. We remark that such a feature can only be revealed from spectral EKE budget analysis so that it is overlooked in previous literature analyzing EKE budget in the physical space (e.g., von Storch et al. 2012; Chen et al. 2014; Wu et al. 2017). However, its underlying mechanisms remain unclear and deserve further analysis in future studies.

\section{Conclusions}

In this study, the global spectral EKE budget is investigated based on high-resolution general circulation models. The major conclusions are summarized as follows:

1) At all the latitudes, the barotropic energy conversion from the background flow to oceanic eddies is positive throughout the wavenumber space and generally peaks around the eddy energy containing scale $L_{e}$ (the scale where the EKE reaches its maximum).

2) The baroclinic energy conversion is more pronounced at midlatitudes. At the midlatitudes, the baroclinic energy conversion is dominated by a dipolar structure with positive and negative values at scales smaller and larger than $L_{e}$, respectively. 

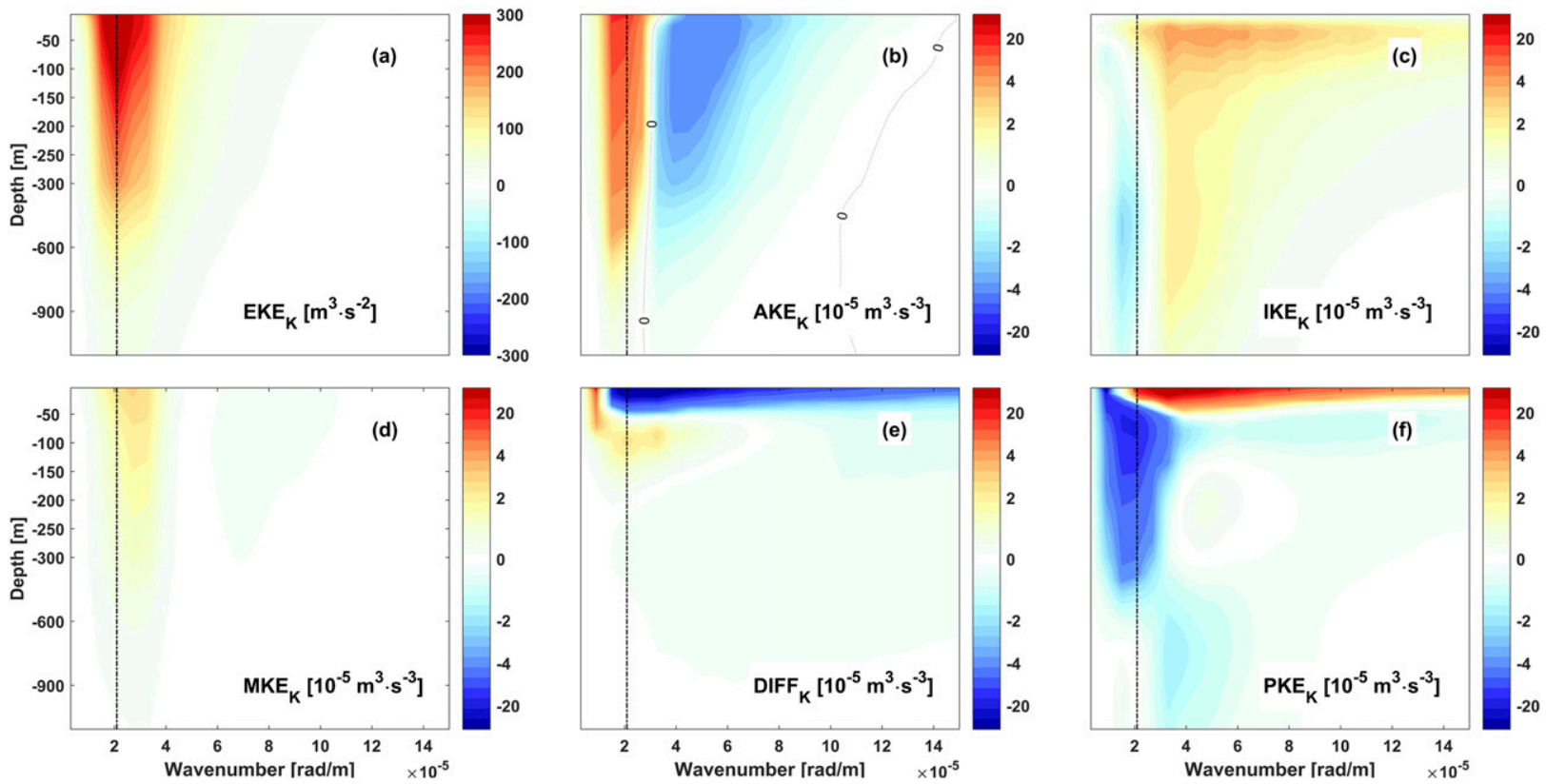

FIG. 6. Vertical distributions of (a) $\mathrm{EKE}_{K}$, (b) $\mathrm{AKE}_{K}$, (c) $\mathrm{IKE}_{K}$, (d) $\mathrm{MKE}_{K}$, (e) $\mathrm{DIFF}_{K}$, and (f) $\mathrm{PKE}_{K}$ averaged over the midlatitudes (latitudes $>10^{\circ}$ ). The vertical dashed line is the eddy energy containing wavenumber $1 / L_{e}$. The results are derived from the 4 -yr CESM simulations.

3) The viscous effect plays a dual role in the spectral EKE budget, dissipating the EKE at scales around and smaller than $L_{e}$ but producing EKE at large scales. This dual role can be understood by decomposing the viscous effect into the surface wind power on geostrophic flow, interior dissipation, and friction by bottom drag. Surface wind power deposits energy into the eddy field at larger scales but leads to EKE loss around $L_{e}$ due to the imprint of the eddy current on wind stress. The interior viscous dissipation and
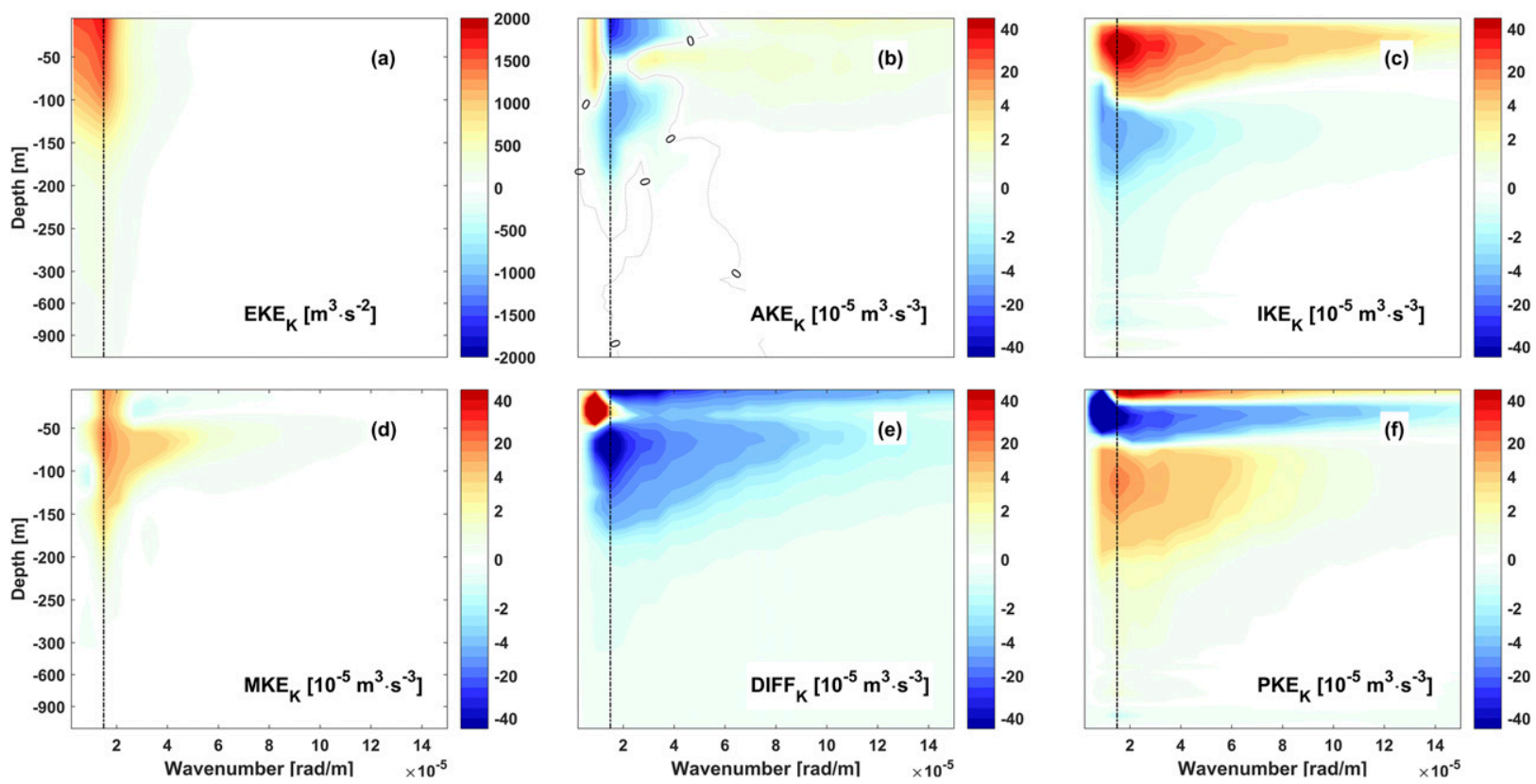

FIG. 7. As in Fig. 6, but for the equatorial region $\left(<10^{\circ}\right)$. 

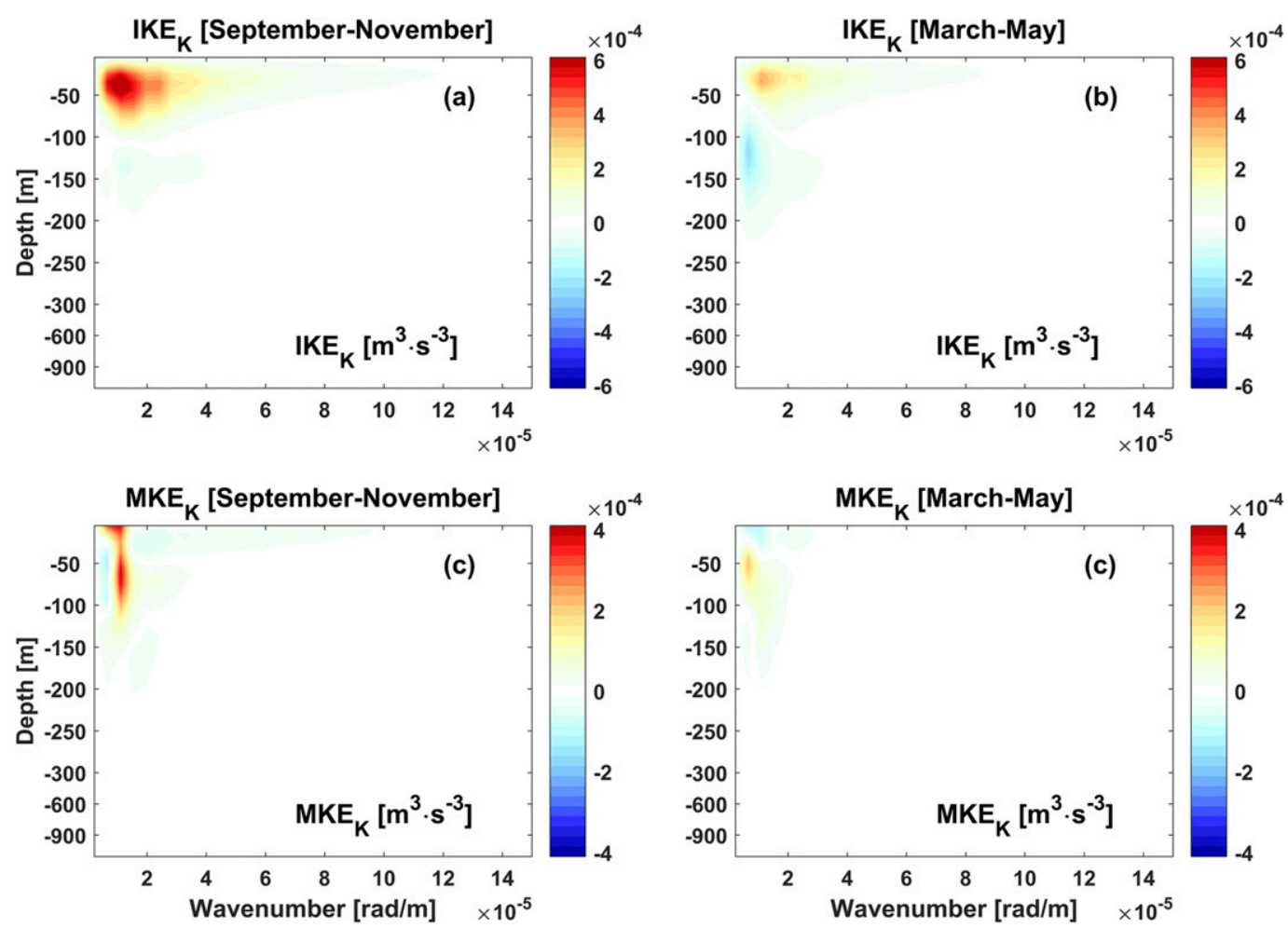

FIG. 8. Vertical distributions of $\operatorname{IKE}_{K}$ term in the equatorial region $\left(<10^{\circ}\right)$ averaged over (a) SeptemberNovember and (b) March-May. (c),(d) As in (a) and (b), but for the $\mathrm{MKE}_{K}$ term. The results are derived from the 4-yr CESM simulations.

bottom drag result in significant EKE loss. The latter is most efficient at $L_{e}$ while the former is more dominant at smaller scales.

4) There is an evident mismatch between the energy source and sink in the spectral space. The energy cascade through the nonlinear advection term plays an important role in balancing the spectral EKE budget. At the midlatitudes, there is a dominant inverse energy cascade. In contrast, the equator region is characterized by a dominant forward energy cascade.

The turbulence characteristics of the ocean motions, especially the nonlinear energy cascade, remain the hot topic over the last two decades. However, limited by sparse in situ measurements, it is difficult to conduct a general survey about the global spectral characteristics of ocean eddy energy. High-resolution GCM simulations provide a viable alternative to perform a complete EKE budget analysis over the horizontal wavenumber space. However, the current generation of GCMs also has their own limitations. Although the inverse energy cascade is mediated by mesoscale eddies that are well resolved by a $1 / 10^{\circ} \mathrm{GCM}$, the forward energy cascade is dominated by submesoscale eddies that are poorly resolved, especially at mid- and high latitudes. Existing studies suggest that the forward energy cascade plays an important role in the energy balance over the global ocean (Müller et al. 2005; Brüggemann and Eden 2015; Barkan et al. 2015). Therefore, a larger

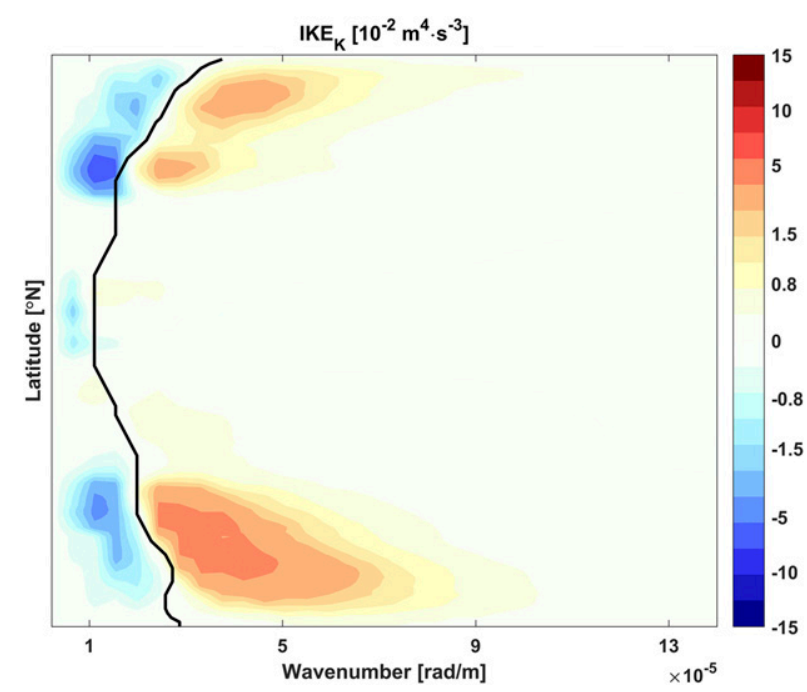

FIG. 9. Vertically integrated $\mathrm{IKE}_{K}$ term calculated from the LICOM data. The black solid line is the eddy energy containing wavenumber $1 / L_{e}$. 
portion of the injected energy through baroclinic and barotropic conversions might be transferred to large scales in numerical models than in observations. Global submesoscale eddy resolving simulations are thus necessary to further improve the accuracy of estimates and the understanding of ocean energy pathway. Such understanding may provide insights into the simulation biases in the current generation of global eddyresolving GCMs.

Acknowledgments. This research is financially supported by the Marine S\&T Fund of Shandong Province for Pilot National Laboratory for Marine Science and Technology (Qingdao) (2018SDKJ0102-7-7), NSFC Projects (41490643, 41490640), National Key Research and Development Program of China (2016YFC1402606), Natural Science Foundation of China (41622602),
AoShan Talents Program (2017ASTCP-ES05), and Fundamental Research Funds for the Central Universities (201762013). The CESM project is supported by the National Science Foundation and the Office of Science (BER) of the U.S. Department of Energy. Computing resources were provided by the Climate Simulation Laboratory at NCAR's Computational and Information Systems Laboratory (CISL), sponsored by the National Science Foundation and other agencies.

\section{APPENDIX A}

\section{Decomposition of the DIFF $_{K}$ Term}

The vertical integral of $\operatorname{DIFF}_{K}$ term between the sea surface $(z=0)$ and an arbitrary vertical level $\left(z=z_{0}\right)$ can be decomposed into the following five terms:

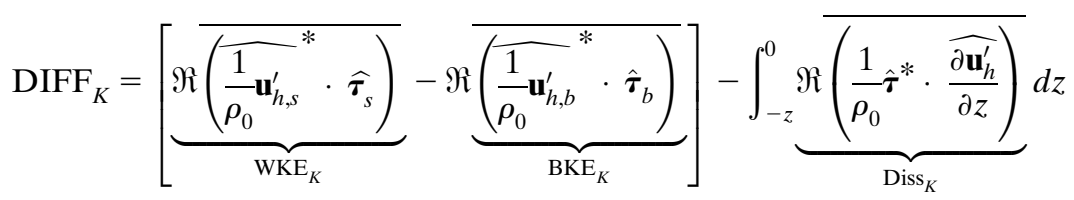

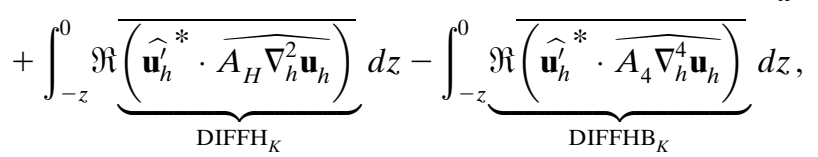

where $A_{H}$ and $A_{4}$ are the horizontal viscosity and horizontal biharmonic viscosity, $\boldsymbol{\tau}$ is the vertical turbulent stress, and the subscripts $s$ and $b$ denote the sea surface and $z=z_{0}$. The first term on the right-hand side of Eq. (A1) corresponds to the wind power. The second term corresponds to the friction due to the bottom drag if $z=z_{0}$ is the sea floor, but would be negligible if $z=z_{0}$ is above the bottom boundary layer as in this study. The third, fourth and fifth terms are generally negative, representing the EKE dissipation within the body of seawater and are referred to as the interior dissipation term in this study.

The $\mathrm{WKE}_{K}$ includes the wind power both on geostrophic flow associated with eddies and on Ekman flow, with the latter an order of magnitude larger than the former (Wang and Huang 2004a,b; Scott and Xu 2009). However, almost all the wind power on Ekman flow is dissipated in the surface Ekman layer, making negligible contribution to the EKE budget (Wang and Huang 2004a,b; Grant and Belcher 2011). For this sake, we substitute $\mathrm{WKE}_{K}$ term in Eq. (A1) by the wind power on geostrophic flow and compute the interior dissipation term as a residue provided that the wind power on Ekman flow and interior dissipation of Ekman flow are almost balanced by each other.

\section{APPENDIX B}

\section{Influence of the Net EKE Transport across Boundaries on the Energy Cascade Inferred from Eq. (2)}

The $\mathrm{AKE}_{K}$ term includes the redistribution of EKE among different wavenumbers and the transport of EKE out of or into the domain. The integral of former over all the wavenumbers is zero, whereas the integral of the latter is nonzero, leading to a nonvanishing $\Pi(0)$. Therefore, the contamination of the energy cascade inferred from Eq. (2) by the net EKE transport across boundaries can be measured as

$$
r=\frac{|\Pi(0)|}{|\Pi(k)|_{\max }},
$$

where $|\Pi(k)|_{\max }$ is the peak value of $\Pi(k)$. A value of $r$ much smaller than unity means that the $\mathrm{AKE}_{K}$ term is dominated by the redistribution of EKE among different wavenumbers, and the net EKE transport across boundaries is unlikely to distort the dominant direction of inferred energy cascade. As shown in Fig. B1, $r$ is less than 0.17 between $60^{\circ} \mathrm{S}$ and $60^{\circ} \mathrm{N}$ and becomes even 


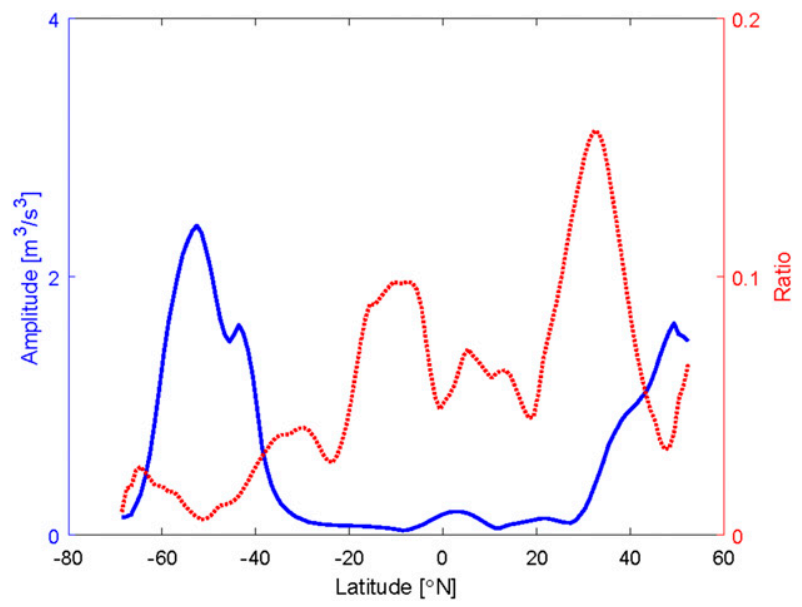

FIG. B1. Latitudinal variation of the $|\Pi(k)|_{\max }$ (blue) and the ratio $r$ (red).

smaller at latitudes with strong eddy activity, providing confidence that the energy cascade inferred from Eq. (2) is qualitatively reliable.

\section{REFERENCES}

Arbic, B. K., and Coauthors, 2009: Estimates of bottom flows and bottom boundary layer dissipation of the oceanic general circulation from global high-resolution models. J. Geophys. Res., 114, C02024, https://doi.org/10.1029/2008JC005072.

Barkan, R., K. B. Winters, and S. G. Llewellyn Smith, 2015: Energy cascades and loss of balance in a reentrant channel forced by wind stress and buoyancy fluxes. J. Phys. Oceanogr., 45, 272293, https://doi.org/10.1175/JPO-D-14-0068.1.

Bell, T., 1975: Topographically generated internal waves in the open ocean. J. Geophys. Res., 80, 320-327, https://doi.org/10.1029/ JC080i003p00320.

Bishop, S. P., F. O. Bryan, and R. J. Small, 2015: Bjerknes-like compensation in the wintertime North Pacific. J. Phys. Oceanogr., 45, 1339-1355, https://doi.org/10.1175/JPO-D-14-0157.1.

Brüggemann, N., and C. Eden, 2015: Routes to dissipation under different dynamical conditions. J. Phys. Oceanogr., 45, 21492168, https://doi.org/10.1175/JPO-D-14-0205.1.

Capet, X., J. C. McWilliams, M. J. Molemaker, and A. Shchepetkin, 2008: Mesoscale to submesoscale transition in the California Current System. Part III: Energy balance and flux. J. Phys. Oceanogr., 38, 2256-2269, https://doi.org/10.1175/2008JPO3810.1.

Charney, J. G., 1971: Geostrophic turbulence. J. Atmos. Sci., 28, 1087-1095, https://doi.org/10.1175/1520-0469(1971)028<1087: GT>2.0.CO;2.

Chelton, D. B., M. G. Schlax, M. H. Freilich, and R. F. Milliff, 2004: Satellite measurements reveal persistent small-scale features in ocean winds. Science, 303, 978-983, https://doi.org/10.1126/ science.1091901.

- - — nonlinear mesoscale eddies. Prog. Oceanogr., 91, 167-216, https://doi.org/10.1016/j.pocean.2011.01.002.

Chen, R., G. R. Flierl, and C. Wunsch, 2014: A description of local and nonlocal eddy-mean flow interaction in a global eddypermitting state estimate. J. Phys. Oceanogr., 44, 2336-2352, https://doi.org/10.1175/JPO-D-14-0009.1.
Dewar, W. K., and A. M. Hogg, 2010: Topographic inviscid dissipation of balanced flow. Ocean Modell., 32, 1-13, https:// doi.org/10.1016/j.ocemod.2009.03.007.

Dubovikov, M. S., and V. M. Canuto, 2005: Dynamic model of mesoscale eddies. Eddy parameterization for coarse resolution ocean circulation models. Geophys. Fluid Dyn., 99, 19-47, https://doi.org/10.1080/03091920412331336406.

Eady, E. T., 1949: Long waves and cyclone waves. Tellus, 1, 33-52, https://doi.org/10.3402/tellusa.v1i3.8507.

Fjørtoft, R., 1953: On the changes in the spectral distribution of kinetic energy for two-dimensional, nondivergent flow. Tellus, 5, 225-230, https://doi.org/10.3402/tellusa.v5i3.8647.

Frenger, I., N. Gruber, R. Knutti, and M. Münnich, 2013: Imprint of Southern Ocean eddies on winds, clouds and rainfall. Nat. Geosci., 6, 608-612, https://doi.org/10.1038/ngeo1863.

Gibson, J. K., P. Kållberg, S. Uppala, A. Hernandez, A. Nomura, and E. Serrano, 1999: ECMWF Re-Analysis Project Report Series: 1. ERA-15 description. ECMWF Doc., 84 pp.

Grant, A. L., and S. E. Belcher, 2011: Wind-driven mixing below the oceanic mixed layer. J. Phys. Oceanogr., 41, 1556-1575, https://doi.org/10.1175/JPO-D-10-05020.1.

Holmes, R., and L. Thomas, 2016: Modulation of tropical instability wave intensity by equatorial Kelvin waves. J. Phys. Oceanogr., 46, 2623-2643, https://doi.org/10.1175/JPO-D-16-0064.1.

Jayne, S. R., and J. Marotzke, 2002: The oceanic eddy heat transport. J. Phys. Oceanogr., 32, 3328-3345, https://doi.org/10.1175/ 1520-0485(2002)032<3328:TOEHT>2.0.CO;2.

Jones, J. H., 1973: Vertical mixing in the equatorial undercurrent. J. Phys. Oceanogr., 3, 286-296, https://doi.org/10.1175/ 1520-0485(1973)003<0286:VMITEU>2.0.CO;2.

Klein, P., B. L. Hua, G. Lapeyre, X. Capet, S. Le Gentil, and H. Sasaki, 2008: Upper-ocean turbulence from high-resolution 3D simulations. J. Phys. Oceanogr., 38, 1748-1763, https:// doi.org/10.1175/2007JPO3773.1.

Kolmogorov, A. N., 1991: Dissipation of energy in the locally isotropic turbulence. Proc. Roy. Soc. London, 434A, 15-17, https://doi.org/10.1098/rspa.1991.0076.

Large, W. G., and S. G. Yeager, 2004: Diurnal to decadal global forcing for ocean and sea-ice models: The data sets and flux climatologies. Tech. Note NCAR/TN-460+STR, 105 pp., https://doi.org/10.5065/D6KK98Q6.

Liu, C., K. Armin, Z. Liu, F. Wang, and S. Detlef, 2016: Deep-reaching thermocline mixing in the equatorial pacific cold tongue. Nat. Commun., 7, 11576, https://doi.org/10.1038/ncomms11576.

Liu, H., Y. Yu, P. Lin, and F. Wang, 2014: High-Resolution LICOM. Flexible Global Ocean-Atmosphere-Land System Model, Springer, 321-331 pp., https://doi.org/10.1007/978-3642-41801-3_38.

Marchesiello, P., X. Capet, C. Menkes, and S. C. Kennan, 2011: Submesoscale dynamics in tropical instability waves. Ocean Modell., 39, 31-46, https://doi.org/10.1016/j.ocemod.2011.04.011.

Masina, S., S. G. H. Philander, and A. B. G. Bush, 1999: An analysis of tropical instability waves in a numerical model of the Pacific Ocean 2. Generation and energetics of the waves. J. Geophys. Res., 104, 29 637-29 661, https://doi.org/10.1029/1999JC900226.

Meijers, A., N. Bindoff, and J. Roberts, 2007: On the total, mean, and eddy heat and freshwater transports in the Southern Hemisphere of a $1 / 8^{\circ} \times 1 / 8^{\circ}$ global ocean model. J. Phys. Oceanogr., 37, 277-295, https://doi.org/10.1175/JPO3012.1.

Molemaker, M. J., J. McWilliams, and C. James, 2010: Balanced and unbalanced routes to dissipation in an equilibrated Eady flow. J. Fluid Mech., 654, 35-63, https://doi.org/10.1017/ S0022112009993272. 
Müller, P., J. C. McWilliams, and M. J. Molemaker, 2005: Routes to dissipation in the ocean: The 2D/3D turbulence conundrum. Marine Turbulence: Theories, Observations, and Models, H. Z. Baumert, J. Simpson, and J. Sündermann, Eds., Cambridge University Press, 397-405.

Ni, R., G. A. Voth, and N. T. Ouellette, 2014: Extracting turbulent spectral transfer from under-resolved velocity fields. Phys. Fluids, 26, 105107, https://doi.org/10.1063/1.4898866.

Nikurashin, M., and R. Ferrari, 2011: Global energy conversion rate from geostrophic flows into internal lee waves in the deep ocean. Geophys. Res. Lett., 38, L08610, https://doi.org/10.1029/ 2011 GL046576.

Philander, S. G. H., 1978: Instabilities of zonal equatorial currents. J. Geophys. Res., 83, 3679-3682, https://doi.org/10.1029/ JC083iC07p03679.

Rhines, P. B., 1977: The dynamics of unsteady currents. Marine Modeling, E. D. Goldberg, Ed., The Sea-Ideas and Observations on Progress in the Study of the Seas, Vol. 6, Wiley, 189-318.

Roske, F., 2001: An atlas of surface fluxes based on the ECMWF re-analysis? A climatological dataset of force global ocean general circulation models. Max-Planck Institut fur Meteorologie Rep. 323, 26 pp.

Roullet, G., J. C. McWilliams, X. Capet, and M. J. Molemaker, 2012: Properties of steady geostrophic turbulence with isopycnal outcropping. J. Phys. Oceanogr., 42, 18-38, https:// doi.org/10.1175/JPO-D-11-09.1.

Schlösser, F., and C. Eden, 2007: Diagnosing the energy cascade in a model of the North Atlantic. Geophys. Res. Lett., 34, L02604, https://doi.org/10.1029/2006GL027813.

Scott, R. B., and F. Wang, 2005: Direct evidence of an oceanic inverse kinetic energy cascade from satellite altimetry. $J$. Phys. Oceanogr., 35, 1650-1666, https://doi.org/10.1175/JPO2771.1.

— surface geostrophic flow of the World Ocean. Deep-Sea Res. I, 56, 295-304, https://doi.org/10.1016/j.dsr.2008.09.010.

Small, R. J., R. A. Tomas, and F. O. Bryan, 2014: Storm track response to ocean fronts in a global high-resolution climate model. Climate Dyn., 43, 805-828, https://doi.org/10.1007/ s00382-013-1980-9.

Smith, K. S., 2007: The geography of linear baroclinic instability in earth's oceans. J. Mar. Res., 65, 655-683, https://doi.org/ 10.1357/002224007783649484.

Stammer, D., 1998: On eddy characteristics, eddy transports, and mean flow properties. J. Phys. Oceanogr., 28, 727-739,
https://doi.org/10.1175/1520-0485(1998)028<0727:OECETA $>$ 2.0.CO;2.

Sumata, H., and Coauthors, 2010: Effect of eddy transport on the nutrient supply into the euphotic zone simulated in an eddypermitting ocean ecosystem model. J. Mar. Syst., 83, 67-87, https://doi.org/10.1016/j.jmarsys.2010.07.002.

Tulloch, R., J. Marshall, C. Hill, and K. S. Smith, 2011: Scales, growth rates, and spectral fluxes of baroclinic instability in the ocean. J. Phys. Oceanogr., 41, 1057-1076, https://doi.org/ 10.1175/2011JPO4404.1.

von Storch, J. S., C. Eden, I. Fast, H. Haak, D. Hernaìndez-Deckers, E. Maier-Reimer, J. Marotzke, and D. Stammer, 2012: An estimate of the Lorenz energy cycle for the world ocean based on the $1 / 10$ STORM/NCEP simulation. J. Phys. Oceanogr., 42, 2185-2205, https://doi.org/10.1175/JPO-D-12-079.1.

Wang, W., and R. X. Huang, 2004a: Wind energy input to the Ekman layer. J. Phys. Oceanogr., 34, 1267-1275, https://doi.org/10.1175/ 1520-0485(2004)034<1267:WEITTE > 2.0.CO;2.

, and,$- 2004 \mathrm{~b}$ : Wind energy input to the surface waves. J. Phys. Oceanogr., 34, 1276-1280, https://doi.org/10.1175/ 1520-0485(2004)034<1276:WEITTS > 2.0.CO;2.

Wang, S., Z. Liu, and C. Pang, 2015: Geographical distribution and anisotropy of the inverse kinetic energy cascade, and its role in the eddy equilibrium processes. J. Geophys. Res. Oceans, $\mathbf{1 2 0}$, 4891-4906, https://doi.org/10.1002/2014JC010476.

_, Z. Jing, H. Liu, and L. Wu, 2018: Spatial and seasonal variations of submesoscale eddies in the eastern tropical Pacific Ocean. J. Phys. Oceanogr., 48, 101-116, https://doi.org/10.1175/ JPO-D-17-0070.1.

Wu, Y., Z. Wang, and C. Liu, 2017: On the response of the Lorenz energy cycle for the Southern Ocean to intensified westerlies. J. Geophys. Res. Oceans, 122, 2465-2493, https://doi.org/ 10.1002/2016JC012539.

Wunsch, C., and R. Ferrari, 2004: Vertical mixing, energy, and the general circulation of the oceans. Annu. Rev. Fluid Mech., 36, 281-314, https://doi.org/10.1146/annurev.fluid.36.050802.122121.

Yu, Y., H. Liu, and P. Lin, 2012: A quasi-global 1/10 eddyresolving ocean general circulation model and its preliminary results. Chin. Sci. Bull., 57, 3908-3916, https://doi.org/ 10.1007/s11434-012-5234-8.

Zhai, X., and D. P. Marshall, 2013: Vertical eddy energy fluxes in the North Atlantic subtropical and subpolar gyres. J. Phys. Oceanogr., 43, 95-103, https://doi.org/10.1175/ JPO-D-12-021.1. 